\title{
Differentially expressed genes of carpet shell clam Ruditapes decussatus against Perkinsus olseni
}

María Prado-Alvarez, Camino Gestal, Beatriz Novoa, Antonio Figueras

Marine Research Institute. CSIC. Vigo

Spanish National Reference Laboratory for Mollusc Diseases 


\section{Bivalve culture in Galicia (2007)}

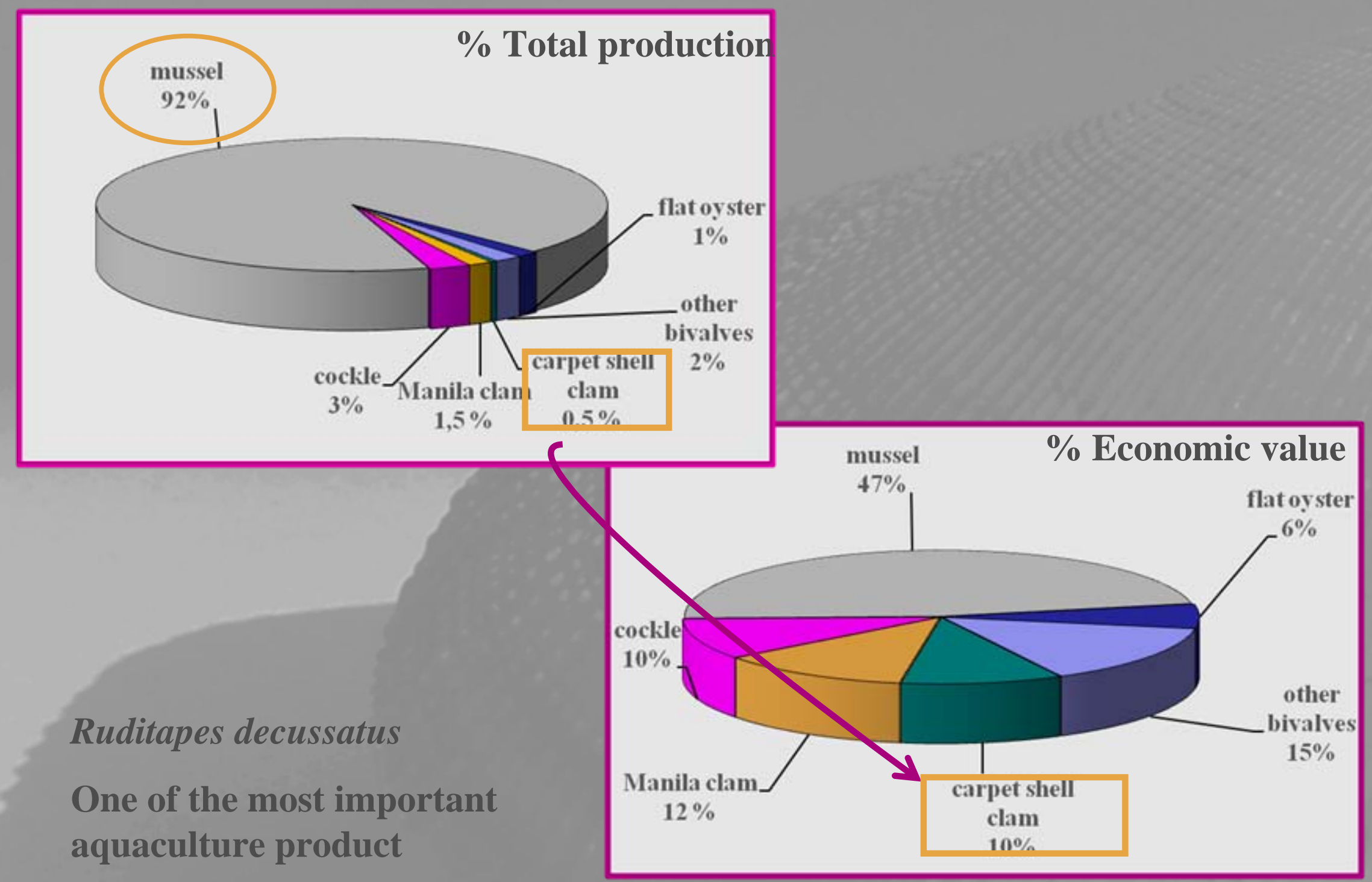


Carpet shell clam production in Galicia

Introduction

Natural beds and ongrowing parks

(1/3 of total production)

Capture volume of $\boldsymbol{R}$. decussatus depends on environmental changes

Increase of the rainfalls

Presence of pathogens

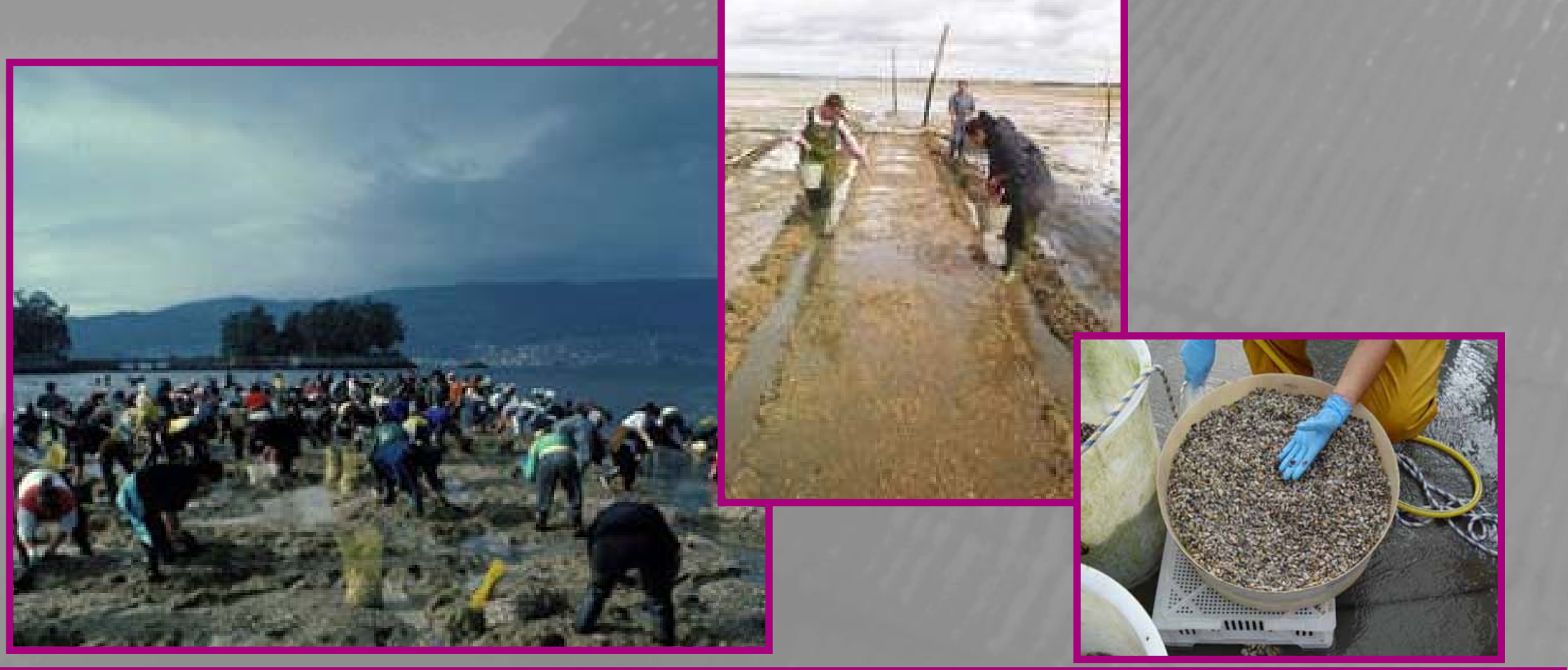

Annual meeting of the National Reference Laboratories for Molluscs Diseases-2010 


\section{Introduction}

Perkinsus species are associated with mass mortalities in molluscs

Susceptible Bivalve species in Europe

Ruditapes decussatus

Ruditapes philippinarum

Ruditapes pullastra

$\checkmark$ enerupis aureus

Cardium edule
Aquatic Animal Health Code 2009 (OIE)

Infection with $P$. olseni is a molluscs disease listed

Ruditapes decussatus is a susceptible specie to the infection of $P$. olseni

\section{Perkinsus olseni $\rightarrow$ Ruditapes decussatus in Spain}

Studies of presence in tissue lessions

Molecular response against the parasite

Identification of genes involved in a Perkinsus olseni infection 


\section{Experimental design}

Naturally infected clams

150 organisms

Infection level: gills in fluid thioglycollate medium(FTM)

Gills and hemocytes were maintained in liquid nitrogen until the results of the infection level

2 groups of $20-25$ clams

Highly infected

Non infected

Haemocytes and gills Haemocytes and gills

Construction of cDNA libraries Suppression subtractive hybridization

Consecutive hybridizations of control and infected samples

Differentially enrichment of expressed transcripts by PCR in

infected samples: forward SSH $\rightarrow$ over-expressed ESTs control sample: reverse SSH $\rightarrow$ down-expressed ESTs 


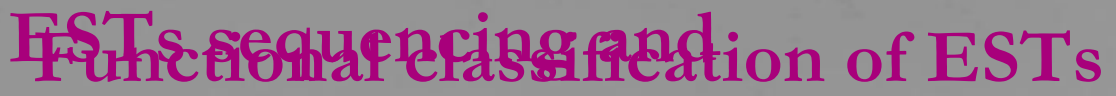 identification}

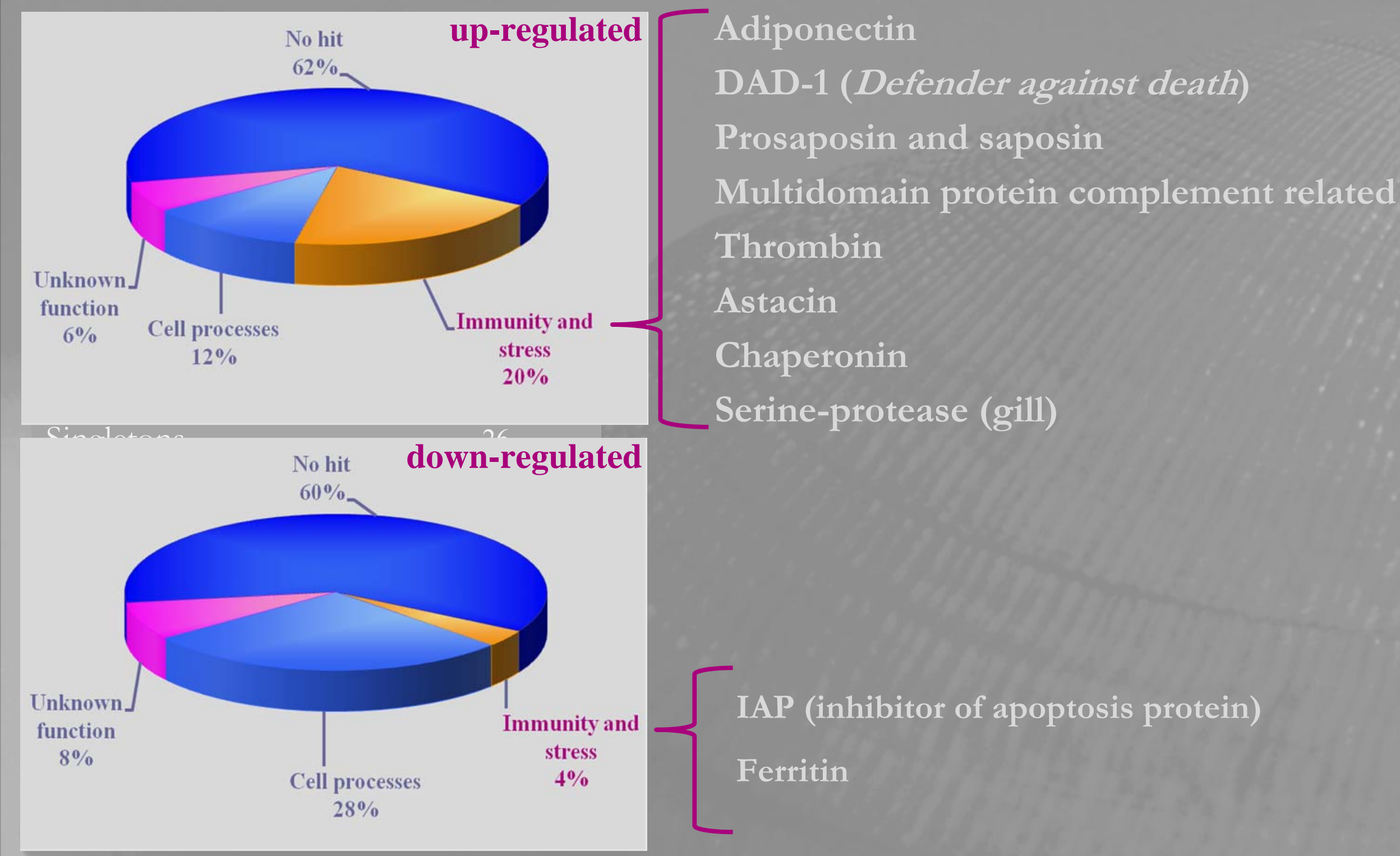


Study of expression of the interested genes qPCR, index of expression

Adiponectin-C1q; DAD-1; prosaposin; multidomain protein complement related; thrombin

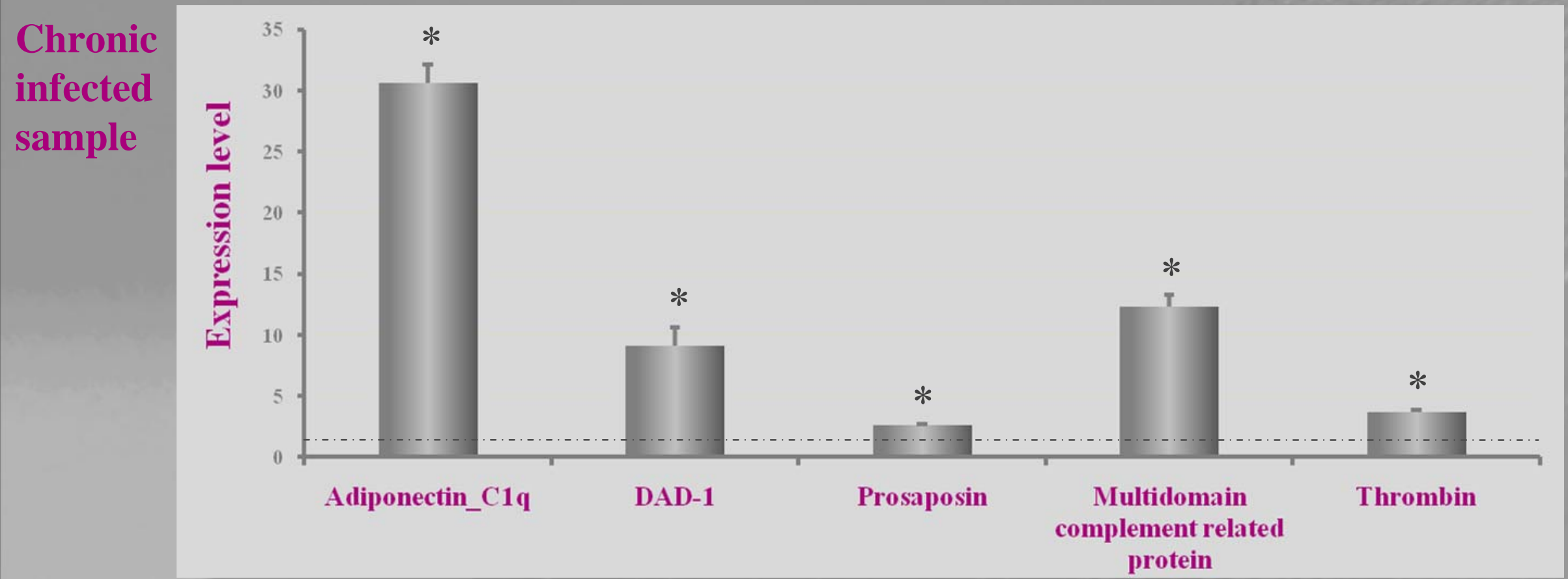

Experimental infection of haemocytes with Perkinsus zoospores 


\section{Experimental design}

Level of infection in clams from a commercial shellfish farm by PCR

\section{infected clams}

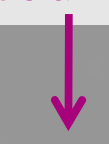

\section{gills}

\section{Perkinsus zoosporulation}

-Incubation in FTM, 5 days, dark, RT

- Centrifugation at $3000 \mathrm{~g} \&$ digestion with $\mathrm{NaOH}$ for 1 hour.

-Maintenance in filtered sea water after

\section{non infected clams}
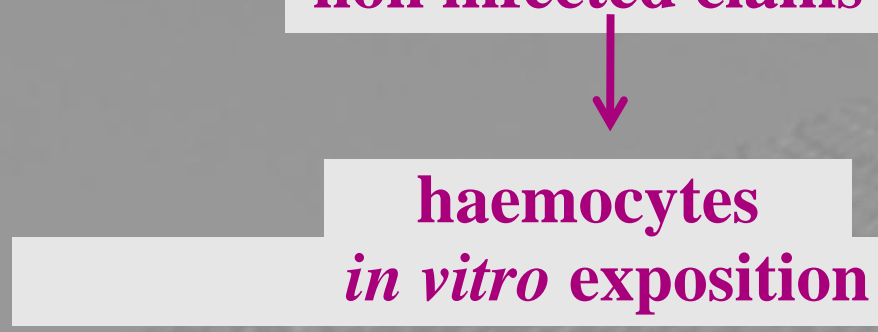

-2 pools of 10 individuals

-Exposition to $10^{8}$ zoospores $/ \mathrm{ml}$. sporulation $\rightarrow$ zoospores

-RNA extraction after $30 \mathrm{~min}, 1,3 \& 24 \mathrm{~h}$

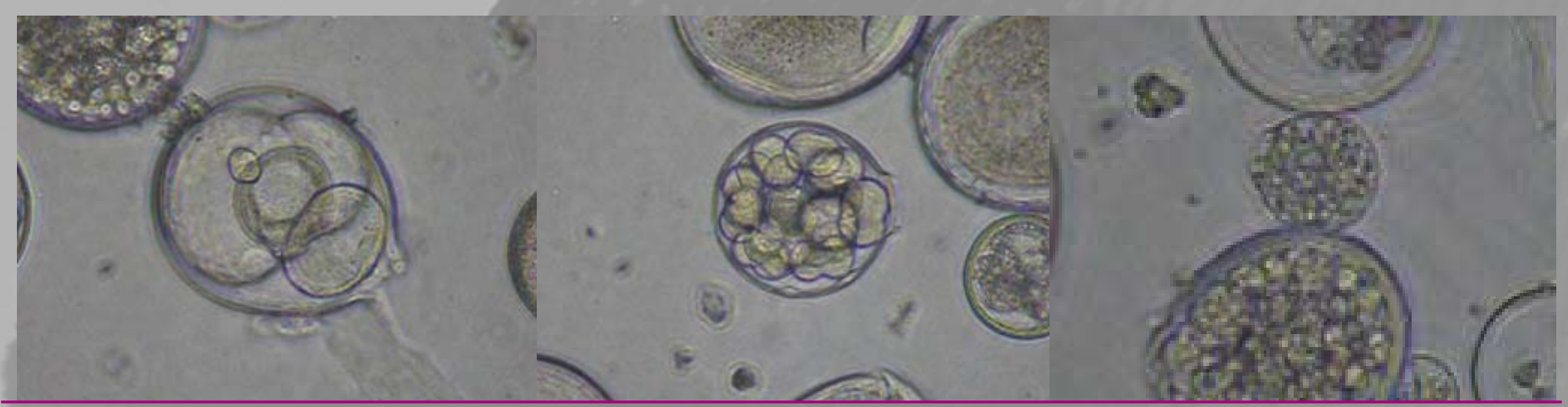

Annual meeting of the National Reference Laboratories for Molluscs Diseases-2010 


\section{Results}

Experimentally infected samples

Chronic infected samples
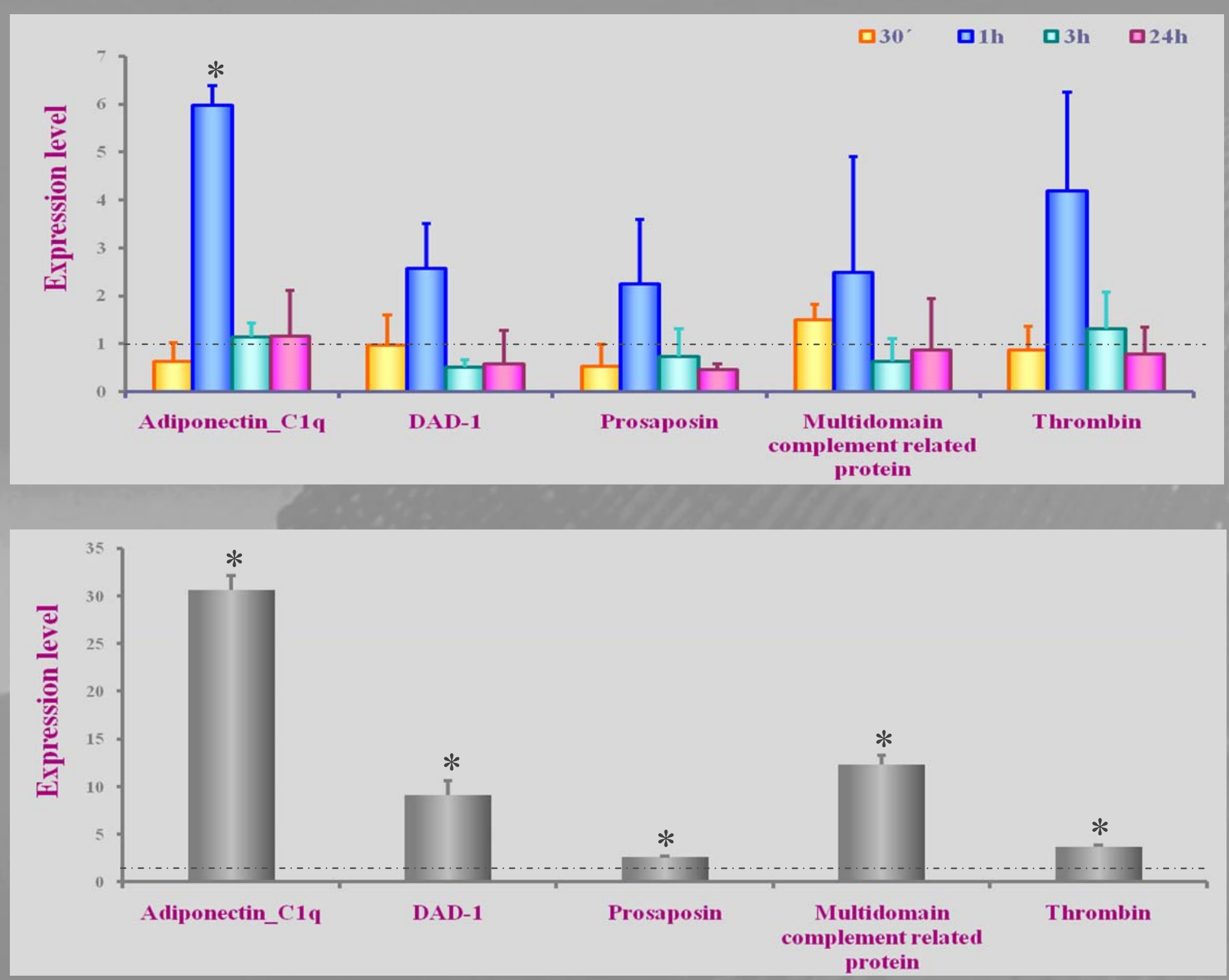


\section{Adiponectin}

- colagen domain and $\mathrm{Clq}$ domain

- similar structure to $\mathrm{C} 1 \mathrm{q}$ and $\mathrm{TNF} \alpha$

\section{3 pares of bases}

211 aa

\section{C1q domain (130 residuos)}

\section{Rd-adiponectin-C1q}

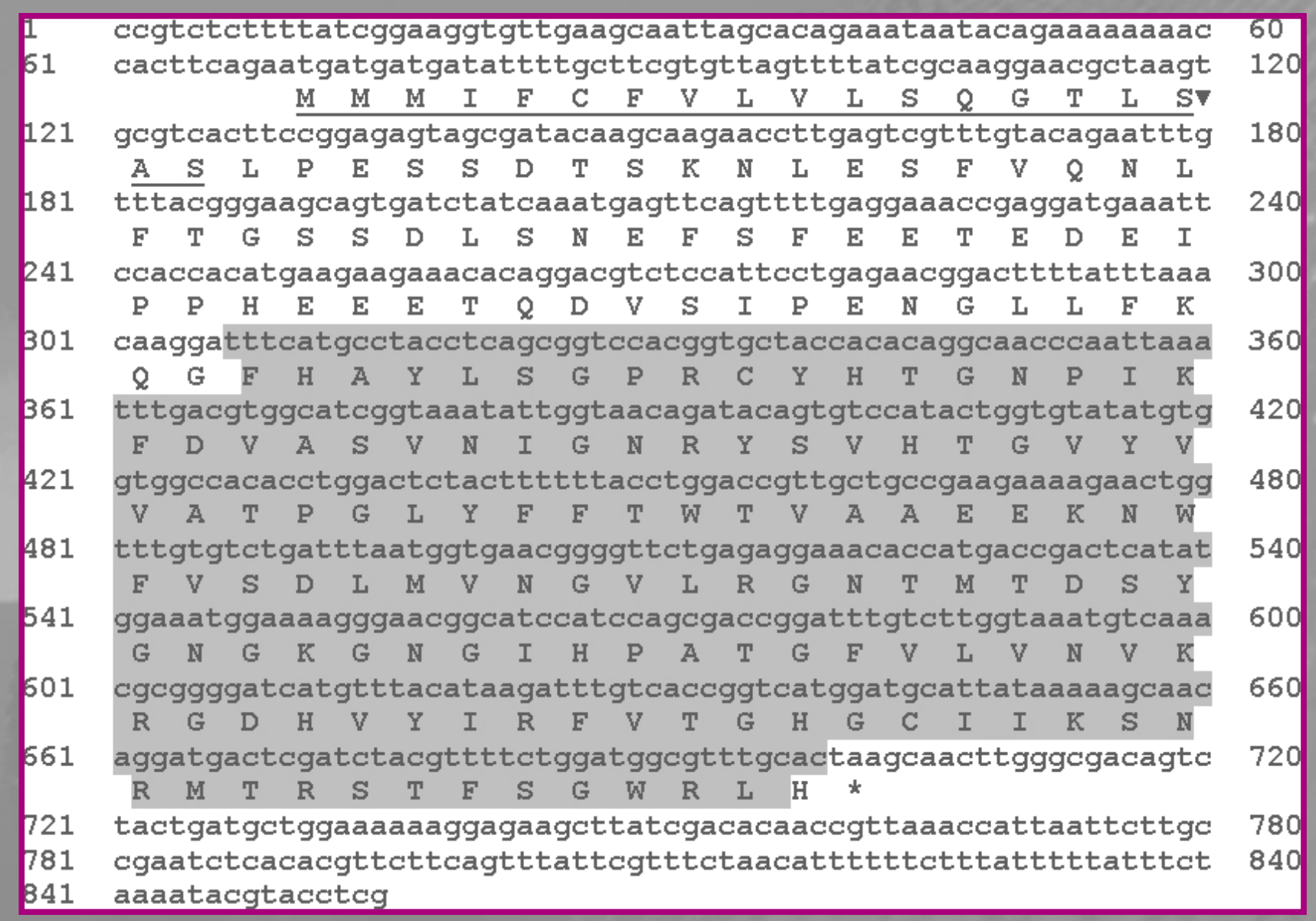

Annual meeting of the National Reference Laboratories for Molluscs Diseases-2010 


\section{Results}

\section{Phylogenetic study. Adiponectina-C1q}

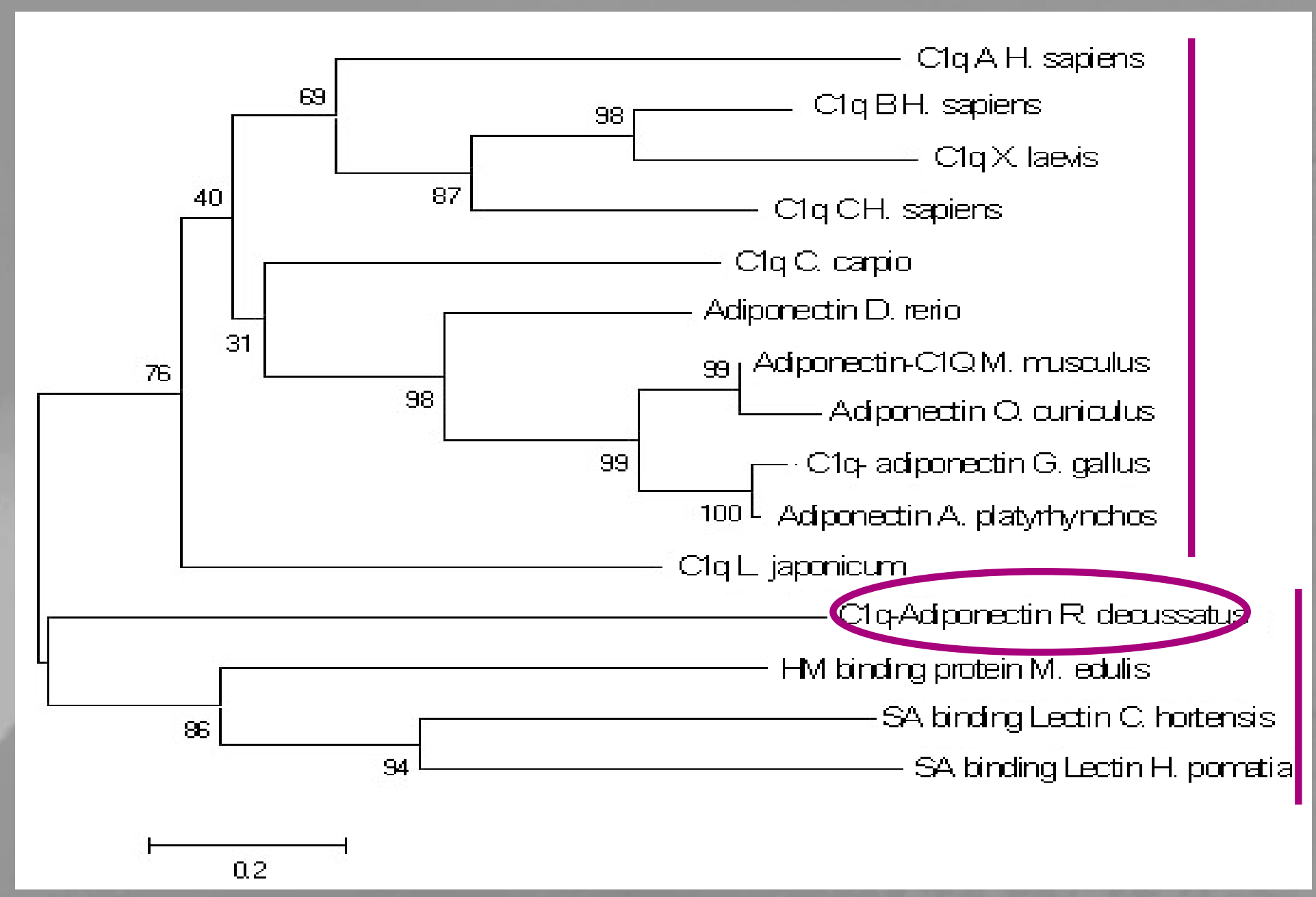




\section{Results}

\section{DAD-1 (Defender against death)}

- apoptosis inhibition

- tissular damage

- heat shock

\section{9 pares of bases}

113 aa

DAD domain

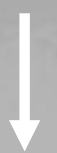

Rd-DAD-1

Phylogenetic study
1 cagcggagaaccagcgatcggtgtctacttccgggaaatgccacgtccaattttctca

61 cttgtttgcaagaaatagcattatttaacaatgccagagaaactaacgggagtcatattc

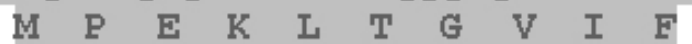

121 aagttttatgacgagtacataacagtactcctaagagactcaaattatagacgcatac $\begin{array}{llllllllllllllllllll}\mathbf{K} & \mathbf{F} & \mathbf{Y} & \mathbf{D} & \mathbf{E} & \mathbf{Y} & \mathbf{I} & \mathbf{N} & \mathbf{S} & \mathbf{T} & \mathbf{P} & \mathbf{K} & \mathbf{R} & \mathbf{L} & \mathbf{K} & \mathbf{I} & \mathbf{I} & \mathbf{D} & \mathbf{A} & \mathbf{Y}\end{array}$

181 ctgctctatatttcctgacaggtgtattcagtttgctattgtgcattggttggaact

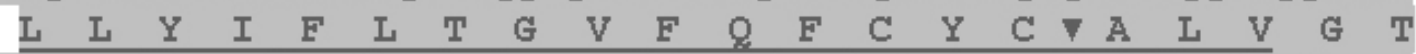

241 ttcccattcaattccttcctgtcagggttcatctcatgtgtaggatctttgttattgca

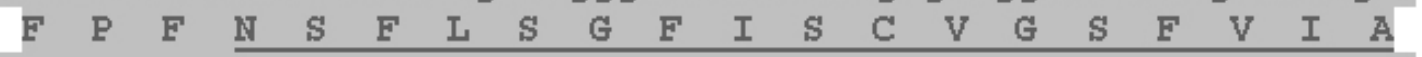

301 gtatgtttaagattacaagtaaatccacagaataagtcagacttttccggcatcagccea

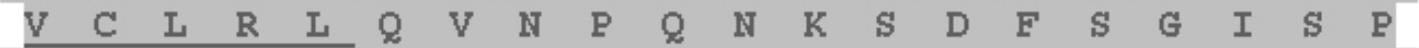

361 gaagagcatttgctgatttatct.cgcaaattggttctacacttggtggttatgaac $\begin{array}{llllllllllllllllllll}\mathbf{E} & \mathbf{R} & \mathbf{A} & \mathbf{F} & \mathrm{A} & \mathrm{D} & \mathbf{F} & \mathrm{I} & \mathbf{F} & \mathbf{A} & \mathbf{N} & \mathrm{L} & \mathrm{V} & \mathrm{L} & \mathrm{H} & \mathrm{L} & \mathrm{V} & \mathrm{V} & \mathbf{M} & \mathbf{N}\end{array}$

421 t.cattggttaaatggaccatcttgttggagta 453 F I G *

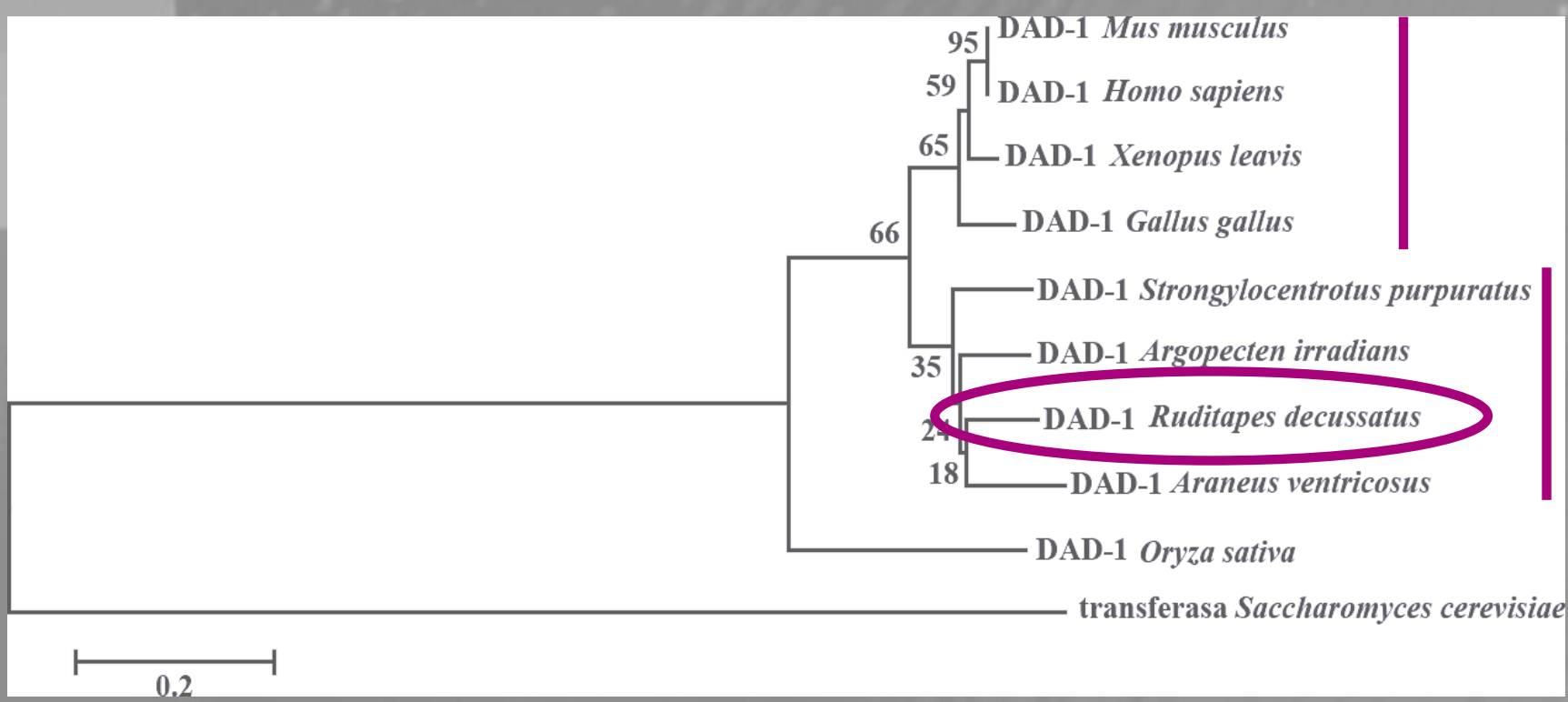

Annual meeting of the National Reference Laboratories for Molluscs Diseases-2010

DAD-1 Homo sapien DAD-1 Xenopus leavis DD-1 Ruditapes decussatus AD-1 Oryza sativa transferasa Saccharomyces cerevisia 0.2 
TUNEL Brown precipitates on DNA breaks

Highly infected clam

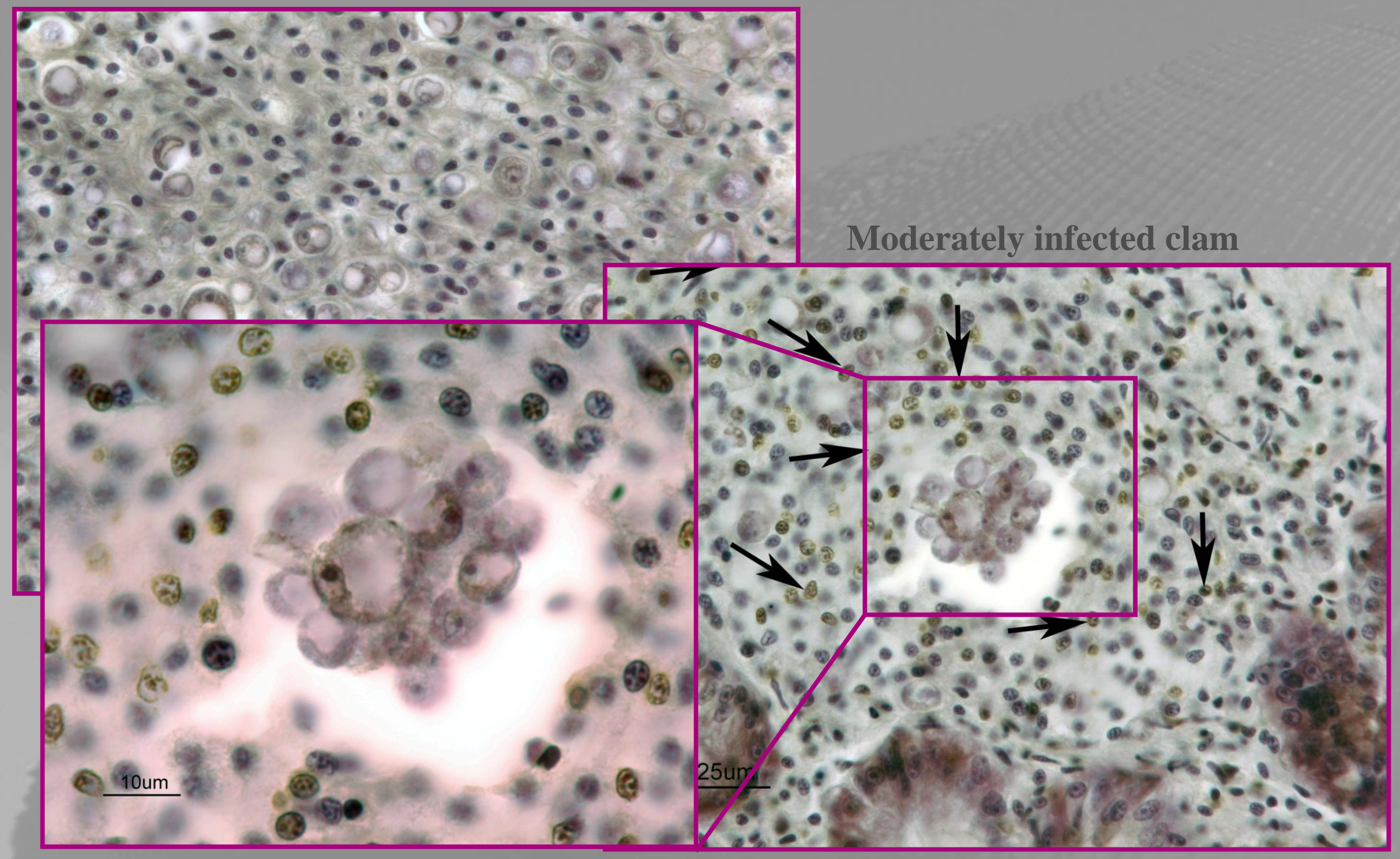

Annual meeting of the National Reference Laboratories for Molluscs Diseases-2010 


\section{Conclusions}

- Most of the identified sequences were found in haemocytes and less in gill

- Similar gene expression pattern in natural and experimentally infected samples

-1 h of exposition provides the highest expression of related immune genes

-Chronic infected clams seem to be in an alert state

-Apoptosis: important process during Perkinsus infection

- Future studies: new identified genes could be used like candidate genes against disease 
Thank you for your attention 